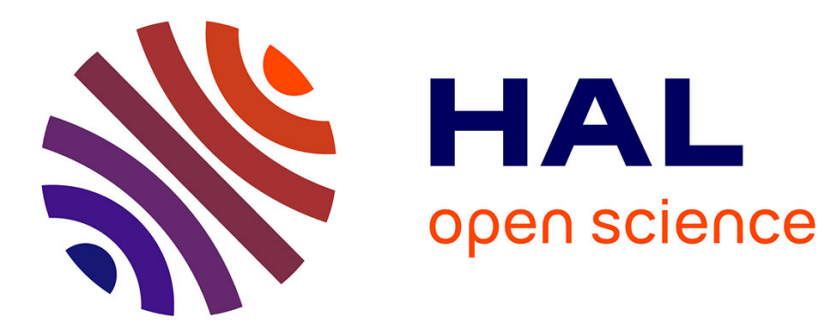

\title{
Atmospheric dynamics triggered by an oceanic SST front in a moist quasigeostrophic model
}

\author{
Bruno Deremble, Guillaume Lapeyre, Michael Ghil
}

\section{To cite this version:}

Bruno Deremble, Guillaume Lapeyre, Michael Ghil. Atmospheric dynamics triggered by an oceanic SST front in a moist quasigeostrophic model. Journal of the Atmospheric Sciences, 2012, 69 (5), pp.1617-1632. 10.1175/JAS-D-11-0288.1 . hal-01111220

\author{
HAL Id: hal-01111220 \\ https://hal.science/hal-01111220
}

Submitted on 29 Jan 2015

HAL is a multi-disciplinary open access archive for the deposit and dissemination of scientific research documents, whether they are published or not. The documents may come from teaching and research institutions in France or abroad, or from public or private research centers.
L'archive ouverte pluridisciplinaire HAL, est destinée au dépôt et à la diffusion de documents scientifiques de niveau recherche, publiés ou non, émanant des établissements d'enseignement et de recherche français ou étrangers, des laboratoires publics ou privés. 


\title{
Atmospheric Dynamics Triggered by an Oceanic SST Front in a Moist Quasigeostrophic Model
}

\author{
Bruno Deremble, * Guillaume Lapeyre, and Michael Ghil ${ }^{+}$ \\ Laboratoire de Météorologie Dynamique/IPSL, Ecole Normale Supérieure/CNRS/UPMC, Paris, France
}

(Manuscript received 8 October 2010, in final form 16 November 2011)

\begin{abstract}
To understand the atmospheric response to a midlatitude oceanic front, this paper uses a quasigeostrophic (QG) model with moist processes. A well-known, three-level QG model on the sphere has been modified to include such processes in an aquaplanet setting. Its response is analyzed in terms of the upper-level atmospheric jet for sea surface temperature (SST) fronts of different profiles and located at different latitudes.

When the SST front is sufficiently strong, it tends to anchor the mean atmospheric jet, suggesting that the jet's spatial location and pattern are mainly affected by the latitude of the SST front. Changes in the jet's pattern are studied, focusing on surface sensible heat flux and on moisture effects through latent heat release. It is found that latent heat release due to moist processes is modified when the SST front is changed, and this is responsible for the meridional displacement of the jet. Moreover, both latent heat release and surface sensible heat flux contribute to the jet's strengthening. These results highlight the role of SST fronts and moist processes in affecting the characteristics of the midlatitude jet stream and of its associated storm track, particularly their positions.
\end{abstract}

\section{Introduction and motivation}

Over the last few years, the emphasis of air-sea interaction studies has shifted from the effect of sea surface temperature (SST) anomalies occurring over large portions of an ocean basin to the effect of SST fronts such as the Gulf Stream or the Kuroshio Extension (Feliks et al. 2004, 2007; Nakamura et al. 2004; Minobe et al. 2008; Brayshaw et al. 2008; Hotta and Nakamura 2011). Several studies (Sweet et al. 1981; Businger and Shaw 1984) noted that the asymmetry in the SST profile creates an unequal heating of the atmospheric lower layers on either side of the front. This differential heating is transmitted to the troposphere through several processes, such as wind convergence in the boundary layer or moist convection.

In most studies of the preceding decades, midlatitude SST anomalies were only found to influence the marine

\footnotetext{
* Current affiliation: Department of Earth, Ocean and Atmospheric Science, Florida State University, Tallahassee, Florida.

Additional affiliation: Department of Atmospheric and Oceanic Sciences and Institute of Geophysics and Planetary Physics, University of California, Los Angeles, Los Angeles, California.
}

Corresponding author address: Guillaume Lapeyre, LMD/IPSL, Ecole Normale Supérieure, 24 Rue Lhomond, 75005 Paris, France. E-mail: glapeyre@lmd.ens.fr atmospheric boundary layer (MABL), while the impact at the top of the troposphere was quite weak (Frankignoul 1985; Palmer and Sun 1985; Kushnir and Lau 1992; Rodwell et al. 1999; Kushnir et al. 2002). More recently, several studies have shown that a nonnegligible part of midlatitude atmospheric eddy activity can be attributed to the underlying SST pattern (Nakamura et al. 2004; Sampe et al. 2010).

In fact, if an SST anomaly can trigger a local atmospheric response that is sufficiently deep, then the local response can excite synoptic waves that affect, in turn, the atmospheric general circulation and the jet streams [as for tropical SST anomalies, see Held et al. (2002)].

Two main ingredients drive the position and the amplitude of the midlatitude jet streams: the large-scale Hadley circulation and the presence of baroclinic eddies. The Hadley circulation gives rise to a subtropical jet (STJ), whose position and amplitude are fairly robust and slowly varying. The STJ, in turn, creates on its poleward side a zone of rapidly growing baroclinic eddies that tend to produce a secondary jet, called the polar-front jet (PFJ) (e.g., Son and Lee 2005; Walker and Schneider 2006). This double-jet structure has been studied in idealized quasigeostrophic (QG) models (Koo and Ghil 2002; Kravtsov et al. 2005), which helped explain it by the presence of multiple equilibria in a $\beta$-channel configuration. The predictions of these models were evaluated in 
the Southern Hemisphere (SH) by Koo et al. (2002) and in the Northern Hemisphere (NH) by Kravtsov et al. (2006).

As mentioned above, however, a nonuniform SSTand especially the presence of strong SST gradients-can displace the baroclinic zones because of the difference in vertical heat fluxes between the cold and the warm sides of the front. Several studies have quantified the influence of this differential heating: Son and Lee (2005), for instance, used different intensities of tropical heating and high-latitude cooling and showed that, in certain configurations, it is possible to separate the PFJ from the STJ and thus to obtain a double-jet structure.

Brayshaw et al. (2008) studied how the position of the atmospheric jet is affected by underlying SST anomalies in a general circulation model (GCM) on an aquaplanet. Their study showed the importance of the Hadley cell and of the lower-layer baroclinicity. They noted different atmospheric responses, depending on the meridional location of the SST front. These responses were due, at least in part, to the low-level baroclinicity being enhanced over strong SST gradients.

Nakamura et al. $(2004,2008)$ introduced the mechanism of "oceanic baroclinic adjustment" to explain the anchoring of the atmospheric jet by the SST front in the Antarctic polar frontal zone in the southern Indian Ocean. The differential supply of sensible heat by the ocean-from one side of the front to the other-acts to maintain a region of lower-layer baroclinicity above the SST front that favors eddy growth, thus contributing to maintain the storm track at this location. Sampe et al. (2010) discussed the details of this mechanism, while Nonaka et al. (2009) and Taguchi et al. (2009) studied the synoptic processes involved in it.

Caballero and Langen (2005) and Lu et al. (2010) demonstrated that the latitude of the storm track is correlated with the equator-to-pole temperature difference, but also with the mean temperature of the surface. Moreover, the role played by moist processes for setting characteristics of the baroclinic zones is not negligible, as pointed out by several authors (Lapeyre and Held 2004; Son and Lee 2005; Frierson et al. 2006; Schneider et al. 2010; Laîné et al. 2011, hereafter LLR11). In fact, the moist processes-as described in these studies-act as an amplifier of the cyclogenesis and can modify the intensity and spatial pattern of the jet. Since the influx of humidity into the atmosphere is largely due to evaporation from the ocean surface, it is also strongly related to the shape of the SST profile.

The purpose of this paper is to investigate systematically how SST fronts, including their position and intensity, affect the upper-level flow; particular attention is given to the relative role of surface sensible and latent heat fluxes that affect the surface atmospheric heating and the water vapor content of the atmosphere. We vary the prescribed SST profile and show how the atmosphere responds to this change. To do so, we use a QG atmospheric model forced by prescribed SSTs in order to study the details of the adjustment mechanism of the jet's position with respect to the SST front.

We wish to describe the interaction of an extratropical SST front-such as those associated with western boundary currents - with the overlying storm track, while eliminating the interaction with the lower-latitude Hadley cell. A QG model is perfectly appropriate for this purpose.

The paper is structured as follows. In section 2, we describe the three-level QG model on the sphere used in this study; additional details are given in the appendix. In section 3, we perform a parameter-sensitivity study and isolate several types of model response. Concluding remarks follow in section 4 .

\section{The QG3H model}

\section{a. Model description}

In the present study, we use a modified version of the three-level QG model (QG3) on the sphere of Marshall and Molteni (1993, hereafter MM93), with a T42 resolution. Their dry QG3 model describes the evolution of potential vorticity at three pressure-coordinate levels; it is formulated in spherical harmonics and, at a T21 truncation, has more than 1000 degrees of freedom. Despite its simple form, the QG3 model has a fairly realistic climatology and low-frequency variability; the latter compare favorably with observed atmospheric behavior (D'Andrea and Vautard 2001; Kondrashov et al. 2004).

The QG3 model was first adapted by LLR11 to include moist processes and is further adapted here to include air-sea fluxes. This QG3H model version computes the time evolution of the QG potential vorticity (PV) and moisture. The lower atmospheric layer exchanges heat and water vapor with an ocean that has a prescribed SST field. The model so obtained is similar in many respects to the Earth System Models of Intermediate Complexity (EMIC) Climate deBilt (ECBILT) model (Opsteegh et al. 1998) and to those of Ferreira and Frankignoul (2005) and of Maze et al. (2006); the latter two studies, though, did not include moist processes. Given realistic forcing, the moist QG3H model also has a realistic climatology and, at a resolution of T42, synoptic variability as well (e.g., LLR11).

The equation for PV evolution is given by

$$
\frac{\partial q_{i}}{\partial t}=-J\left(\psi_{i}, q_{i}\right)-D\left(\psi_{i}\right)+S_{i}+S_{i}^{\mathrm{LH}}+S_{i}^{\mathrm{SH}}
$$

here $q_{i}$ is the PV and $\psi_{i}$ the QG streamfunction at the three dynamical or "wind" levels $i=200,500$, and $800 \mathrm{hPa}$, 
while $t$ is time and $J$ is the Jacobian operator. We recall that the PV at each level is given by

$$
\begin{aligned}
q_{200}= & \nabla^{2} \psi_{200}+f-\frac{1}{\lambda_{350}^{2}}\left(\psi_{200}-\psi_{500}\right), \\
q_{500}= & \nabla^{2} \psi_{500}+f+\frac{1}{\lambda_{350}^{2}}\left(\psi_{200}-\psi_{500}\right) \\
& -\frac{1}{\lambda_{650}^{2}}\left(\psi_{500}-\psi_{800}\right), \\
q_{800}= & \nabla^{2} \psi_{800}+f+\frac{1}{\lambda_{650}^{2}}\left(\psi_{500}-\psi_{800}\right),
\end{aligned}
$$

where $f$ is the Coriolis parameter and $\lambda_{j}$ is the deformation radius at the two thermodynamical levels $j$, with $\lambda_{350}=650 \mathrm{~km}$ and $\lambda_{650}=400 \mathrm{~km}$. In the following, we will refer also to the upper layer $(300-500 \mathrm{hPa})$ and lower layer (500-800 hPa).

The term $S_{i}$ in Eq. (1) is constant in time and represents the mean radiative forcing on the atmosphere. We choose this forcing here so as to simulate a perpetual winter, with the meridional $\mathrm{PV}$ gradient for the $\mathrm{NH}$ being restored to the prescribed gradients:

$$
\begin{aligned}
& \frac{1}{a} \frac{\partial S_{1}}{\partial \phi}=-\frac{u_{0}}{\tau_{d}} \frac{1}{\lambda_{350}^{2}} \sin ^{2}(\pi \sin \phi), \\
& \frac{1}{a} \frac{\partial S_{2}}{\partial \phi}=\frac{u_{0}}{\tau_{d}}\left(\frac{1}{\lambda_{350}^{2}}-\frac{1}{\lambda_{650}^{2}}\right) \sin ^{2}(\pi \sin \phi), \\
& \frac{1}{a} \frac{\partial S_{3}}{\partial \phi}=\frac{u_{0}}{\tau_{d}} \frac{1}{\lambda_{650}^{2}} \sin ^{2}(\pi \sin \phi) ;
\end{aligned}
$$

where $a$ is the radius of the earth, $\phi$ is the latitude, $\tau_{d}=$ 25 days is the thermal relaxation time scale, and $u_{0}$ is set to $26 \mathrm{~m} \mathrm{~s}^{-1}$ in the $\mathrm{NH}$ and to $13 \mathrm{~m} \mathrm{~s}^{-1}$ in the $\mathrm{SH}$.

The term $D\left(\psi_{i}\right)$ in Eq. (1) parameterizes several dissipative processes: Ekman friction in the lower level, with a time scale of 3 days; thermal dissipation, with a time scale of 25 days (see MM93 for details); and selective (exponential) dissipation that is computed implicitly, as in Smith et al. (2002).

The main difference between our QG3H model and the dry QG3 model of MM93 is due to the two terms $S^{\mathrm{SH}}$ and $S^{\mathrm{LH}}$ in Eq. (1). The term $S^{\mathrm{SH}}$ parameterizes sensible heat exchange with the ocean and it is proportional to the difference between $T_{a}$, the surface air temperature (SAT), and $T_{s}$, the SST; its net effect is to change the

\begin{tabular}{|c|c|c|}
\hline Parameter & Definition & Value \\
\hline$\Delta t$ & Time step of integration & $30 \mathrm{~min}$ \\
\hline$\lambda_{650}$ & $\begin{array}{l}\text { Deformation radius } \\
\text { (lower layer) }\end{array}$ & $400 \mathrm{~km}$ \\
\hline$\lambda_{350}$ & $\begin{array}{l}\text { Deformation radius } \\
\text { (upper layer) }\end{array}$ & $650 \mathrm{~km}$ \\
\hline$C_{d h}$ & Heating drag coefficient & $1.3 \times 10^{-3}$ \\
\hline$C_{d e}$ & $\begin{array}{l}\text { Evaporation drag } \\
\text { coefficient }\end{array}$ & $4.4 \times 10^{-4}$ \\
\hline$\tau_{\mathrm{ek}}$ & $\begin{array}{l}\text { Ekman dissipation time } \\
\text { scale }\end{array}$ & 3 days \\
\hline$\tau_{m}$ & $\begin{array}{l}\text { Moisture exchange time } \\
\text { scale }\end{array}$ & 2 days \\
\hline$\tau_{d}$ & $\begin{array}{l}\text { Radiative time scale for } \\
\text { temperature relaxation }\end{array}$ & 25 days \\
\hline$\partial_{P} \overline{m_{5 / 2}}$ & $\begin{array}{l}\text { Vertical gradient of } \\
\text { humidity (lower layer) }\end{array}$ & $2.4 \times 10^{-4} \mathrm{~g} \mathrm{~kg}^{-1} \mathrm{~Pa}^{-1}$ \\
\hline$\partial_{P} \overline{m_{3 / 2}}$ & $\begin{array}{l}\text { Vertical gradient of } \\
\text { humidity (upper layer) }\end{array}$ & $1.5 \times 10^{-4} \mathrm{~g} \mathrm{~kg}^{-1} \mathrm{~Pa}^{-1}$ \\
\hline
\end{tabular}
thickness of the atmospheric layers (see Ferreira and Frankignoul 2005). The surface flux $E^{\mathrm{SH}}$ of sensible heat is given by

$$
E^{\mathrm{SH}}=\rho_{a} C_{d h} c_{p}\left|\mathbf{u}_{800}\right|\left(T_{s}-T_{a}\right),
$$

TABLE 1. Model parameters, as used here, in QG3H.

with $\rho_{a}$ being the air density, $C_{d h}$ a constant exchange coefficient, $c_{p}$ the heat capacity of the air, and $\left|\mathbf{u}_{800}\right|$ the modulus of the wind at $800 \mathrm{hPa}$, which approximates the magnitude of the surface wind. The flux $E^{\mathrm{SH}}$ from Eq. (4) is assumed to correspond to diabatic heating at $650 \mathrm{hPa}$ only and is converted into PV forcing as described in the appendix.

The SAT field used in Eq. (4) is computed at each grid point by extrapolating linearly the model's temperatures, $T_{350}$ and $T_{650}$ :

$$
T_{a}=T_{650}+\frac{\log (950 / 650)}{\log (650 / 350)}\left(T_{650}-T_{350}\right)
$$

We checked that this formula correctly fits the SATs when using the upper-air temperatures from the ERA-40 reanalysis (Uppala et al. 2005). We also verified that the model dynamics depends only very weakly, if at all, on the choice of the SAT parameterization.

The term $S^{\mathrm{LH}}$ in Eq. (1) parameterizes latent heating due to moist processes. This parameterization is done via the following water vapor equation:

$$
\frac{\partial m_{j}}{\partial t}=-J\left(\psi_{j}, m_{j}\right)-w_{j} \partial_{p} \overline{m_{j}}+\delta_{j}^{650} E-P_{j}-D\left(m_{j}\right),
$$

where $m_{j}$ is the water vapor concentration at the thermodynamical levels $j=350$ and $650 \mathrm{hPa}$, while $w_{j}$ is the vertical velocity computed through an $\omega$ equation (see LLR11). The vertical gradient of humidity $\partial_{p} \bar{m}_{j}$ is taken as constant (cf. Table 1).

This choice allows us to mimic the temperature equation in the QG formulation, for which the static stability is held 
constant (consistent with constant Rossby deformation radii). The evaporative flux $E$ uses $\delta_{j}^{650}=1$ for level $j=$ $650 \mathrm{hPa}$ and $\delta_{j}^{650}=0$ for level $j=350 \mathrm{hPa}$, while $P_{j}$ is the large-scale condensation and $D\left(m_{j}\right)$ is the exchange between the layers. The exchange term is computed in the appendix and we refer to LLR11 for the parameterization of $P$.

The evaporation over the ocean is computed using the classical bulk formula:

$$
E=\rho_{a} C_{d e}\left|\mathbf{u}_{800}\right|\left(m_{s}^{s}-m_{a}\right),
$$

with $C_{d e}$ being a constant exchange coefficient, $m_{s}^{s}$ the saturation specific humidity at the temperature of the sea surface, and $m_{a}$ the specific humidity at the surface. The latter is obtained by letting the relative humidity be constant in the lower layer:

$$
m_{a}=m_{650} \frac{m_{a}^{s}}{m_{650}^{s}} .
$$

The saturation specific humidity is denoted by the superscript $s$ and it is computed by using the ClausiusClapeyron formula. At each thermodynamical level, the latent heat released by large-scale condensation is

$$
E_{j}^{\mathrm{LH}}=L_{c} P_{j},
$$

with $L_{c}$ the latent heat of evaporation/condensation. This quantity is converted into a PV tendency $S^{\mathrm{LH}}$ as shown in the appendix, and parameter values are given in Table 1.

The model is integrated at the spectral resolution of T42 in an aquaplanet configuration with prescribed SST, and we study in detail the mechanisms that are active in the winter hemisphere. Although aquaplanet conditions correspond in fact to the $\mathrm{SH}$ better than to the $\mathrm{NH}$ (Trenberth 1991; Koo et al. 2002), we consider for convenience our QG3H model's winter hemisphere to be the $\mathrm{NH}$. Results are thus presented only for the model's NH.

\section{b. Model climatology}

For the control experiment, we define a reference SST field that only depends on the latitude $\phi$ (Inatsu et al. 2002):

$$
T_{\text {ref }}(\phi)=T_{m}-\Delta_{\mathrm{SST}} \sin ^{2}\left(\phi-\phi_{0}\right),
$$

with $T_{m}=301 \mathrm{~K}$ the maximum temperature and $\Delta_{\mathrm{SST}}=$ $32 \mathrm{~K}$. The SST maximum is shifted away from the equator to $\phi_{0}=8^{\circ} \mathrm{S}$, in order to represent boreal winter conditions. We readjust all SST values below $T_{0}=271.4 \mathrm{~K}$ to equal $T_{0}$. As shown in Fig. 1, the SST profile is thus constant at high latitudes, and the mean NH SST equals $287.3 \mathrm{~K}$.

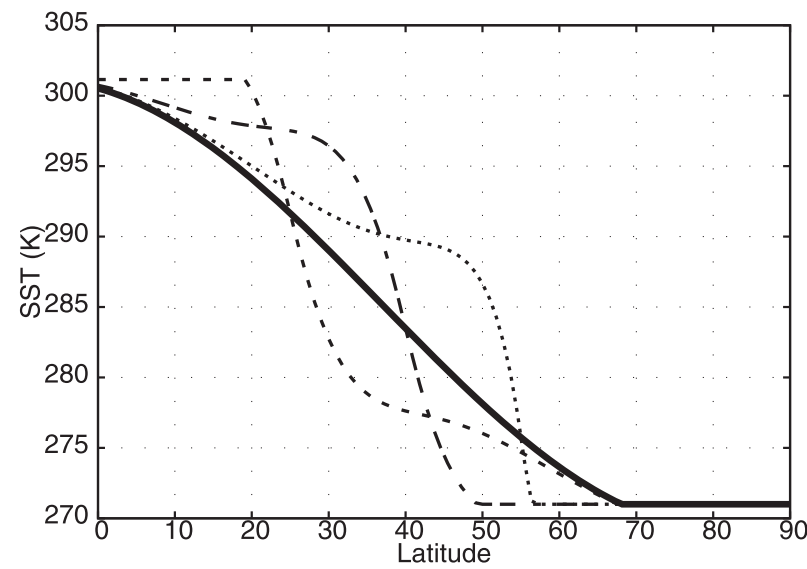

FIG. 1. Meridional SST profiles at the date line $\left(180^{\circ}\right)$ for the NH (i.e., in the center of the zonal extension of the SST fronts of Exp.1, Exp. 2, and Exp. 3). Reference profile $T_{\text {ref }}(\phi)$ (thick solid) and imposed profiles for the three experiments: Exp. 1 (dashed), Exp. 2 (dash-dotted), and Exp. 3 (dotted). See text for details.

In Fig. 2, we present the time mean $\bar{X}$ and the corresponding standard deviation $X^{\mathrm{rms}}$ (no bandpass filter was applied) of several model fields $X(\lambda, \phi, t)$, where $\lambda$ is longitude. These statistics were computed using a 10 000-day-long simulation of the model, after a spinup of 2000 days.

The atmospheric westerly jet at $200 \mathrm{hPa}$ (Figs. 2a and 3a) lies in a broad latitude band, $20^{\circ}-50^{\circ} \mathrm{N}$, with a maximum intensity of $30 \mathrm{~m} \mathrm{~s}^{-1}$ that occurs near $35^{\circ} \mathrm{N}$. This wide band can be decomposed into two parts, as in Son and Lee (2005): the "subpolar" part of the jet around $50^{\circ} \mathrm{N}$, which is maintained by the presence of eddies and whose maximum lies at the same latitude as the storm track (see below), and a "subtropical" part around $30^{\circ} \mathrm{N}$, driven by the radiative forcing $S$ [cf. Eq. (3)]. One can confirm this by looking at Fig. 3, as the subpolar part has a more barotropic signal than the subtropical part. Indeed, if we compute the steady response of the zonal wind to the wind forcing $S_{i}$ and in the absence of eddy forcing - by zeroing out the Jacobian in Eqs. (1) and (6)—only the subtropical part remains (Fig. 2b).

The pattern of the zonal wind at lower levels (not shown) resembles the one plotted in Fig. 2a but the amplitude at $500 \mathrm{hPa}$ is smaller, as seen from Fig. 3b. At $800 \mathrm{hPa}$, the westerly jet is present only north of $22^{\circ} \mathrm{N}$, while an easterly jet occurs south of this latitude (Fig. 3c). This spatial distribution of the winds is consistent with the observations (Peixoto and Oort 1992).

The high values of the standard deviation of the streamfunction at $500 \mathrm{hPa}$ in Fig. 2c allow us to identify the region in which synoptic eddies are most active. Their growth and subsequent downstream development are localized between $20^{\circ}$ and $60^{\circ} \mathrm{N}$. The maximum storm-track 
(a) time-mean $\mathrm{u}$ at $200 \mathrm{hPa}$

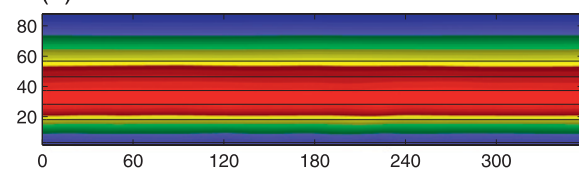

(c) streamfunction rms at $500 \mathrm{hPa}$

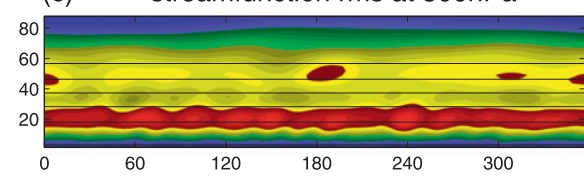

(e) time-mean lower layer moisture

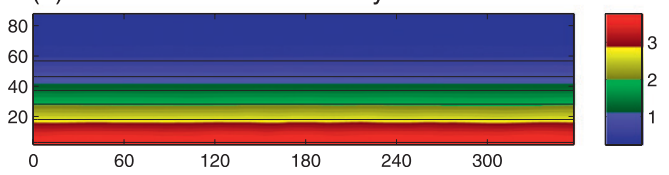

(b) $\quad \mathrm{u}$ (without eddies) at $200 \mathrm{hPa}$

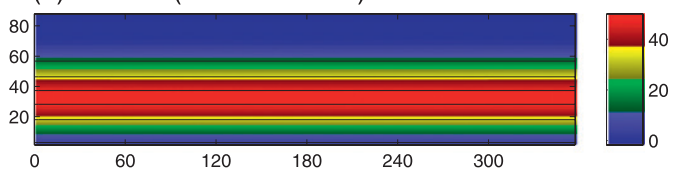

(d) time-mean evaporation

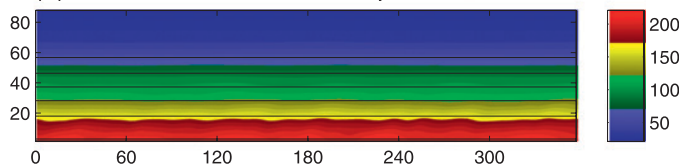

(f) time-mean lower layer condensation

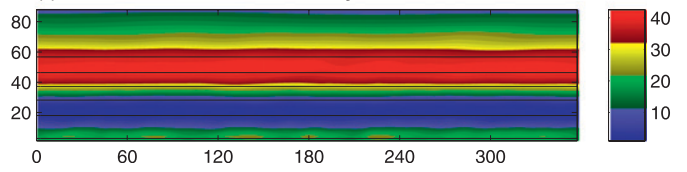

FIG. 2. Mean fields and standard deviations of selected fields for the control-run experiment as a function of longitude and latitude; the solid black contour lines represent the prescribed SST field from 275 to $300 \mathrm{~K}$, every $5 \mathrm{~K}$. (a),(b) Time-mean upper-level wind $\overline{u_{200}}\left(\mathrm{~m} \mathrm{~s}^{-1}\right)$ for (a) the control run and (b) a run without eddy dynamics; (c) standard deviation of midlevel streamfunction $\psi_{500}^{\text {rms }}\left(\mathrm{m}^{2} \mathrm{~s}^{-1}\right)$; (d), (f) time-mean evaporation $\bar{E}$ and condensation $\bar{P}$ $\left(\mathrm{cm} \mathrm{yr}^{-1}\right)$; and (e) lower-layer moisture $\overline{m_{650}}\left(\mathrm{~g} \mathrm{~kg}^{-1}\right)$.

activity at the upper level is shifted equatorward, while it is shifted poleward at the lower level (not shown).

The moisture distribution in the model atmosphere is mainly regulated by evaporation, condensation, and exchange between layers. The evaporation is strong when both the SST and the wind intensity near the surface are high [cf. Eq. (7)]. In Fig. 2d, we see that these two conditions overlap only in a narrow tropical belt. The standard deviation of the evaporation $E^{\mathrm{rms}}$ (not shown) takes high values in the same latitude band as the mean, but it also exhibits another maximum associated with the maximum variability of the surface winds, on the equatorward side of the storm track. This bimodality illustrates the two types of evaporation: in the tropics, it is due to the presence of high SST values, which are also responsible for high values of $m_{s}^{s}$, while at midlatitudes the evaporation is due to the passage of synoptic disturbances.

The mean evaporation rate in the model's NH is about $100 \mathrm{~cm} \mathrm{yr}^{-1}$ and it is only roughly half its value in the observations. The mean amount of moisture at 650 (Fig. 2e) and $350 \mathrm{hPa}$ (not shown) is concentrated equatorward of $30^{\circ} \mathrm{N}$, in the same latitude band as the strongest evaporation. At $650 \mathrm{hPa}$, it reaches the value of $1.5 \mathrm{~g} \mathrm{~kg}^{-1}$ and at $350 \mathrm{hPa}$ that of $3.6 \times 10^{-2} \mathrm{~g} \mathrm{~kg}^{-1}$. In the observations (Peixoto and Oort 1992), typical values at $40^{\circ} \mathrm{N}$ are 2 and $0.125 \mathrm{~g} \mathrm{~kg}^{-1}$, respectively. The mean condensation at (a)

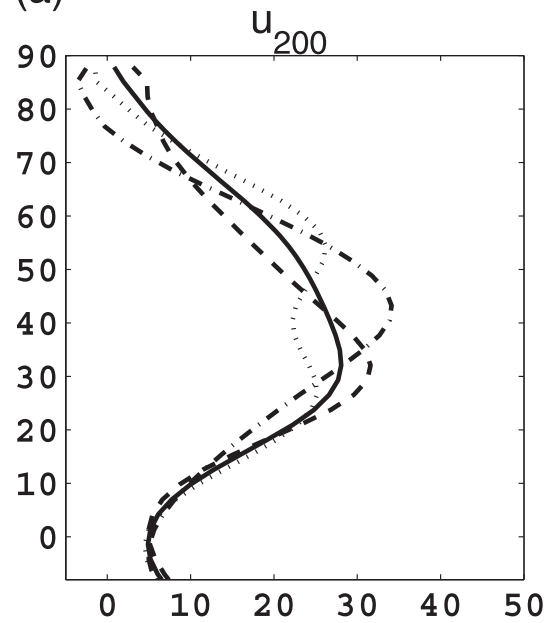

(b)

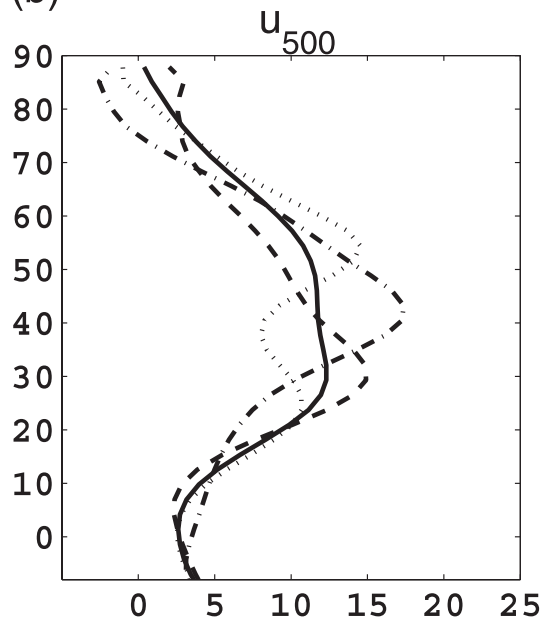

(c)

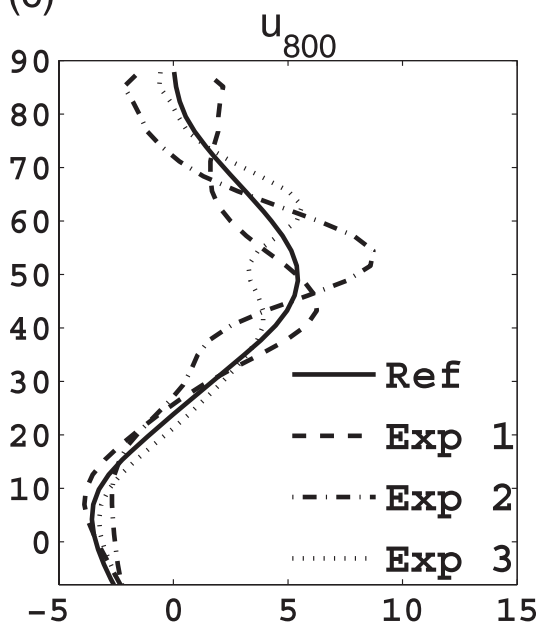

FIG. 3. Zonal wind averaged zonally and in time, with amplitude $\left(\mathrm{m} \mathrm{s}^{-1}\right)$ on the abscissa and latitude on the ordinate, for (a) 200, (b) 500, and (c) $800 \mathrm{hPa}$, showing the control run (solid line), Exp. 1 (dashed), Exp. 2 (dash-dotted), and Exp. 3 (dotted). 
(a) upper level CTRL

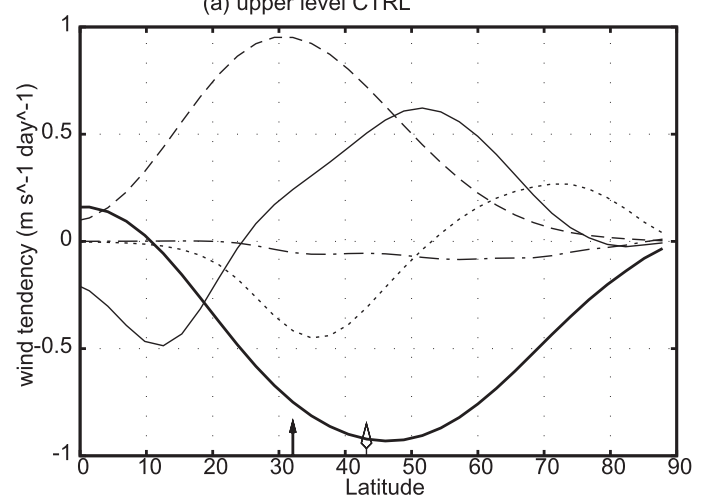

(b) lower level CTRL

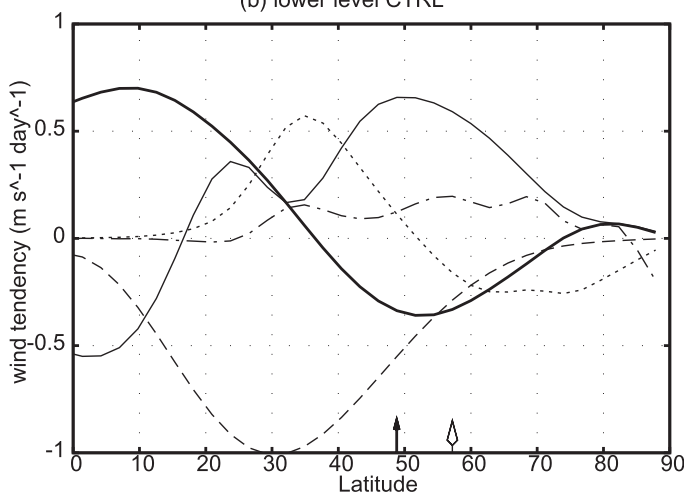

FIG. 4. Zonal and temporal mean of each term entering the zonal momentum budget [rhs of Eq. (10)], for the control run (each term is in $\mathrm{m} \mathrm{s}^{-1} \mathrm{day}^{-1}$ ), for the (a) 200- and (b) 800-hPa levels: Eliassen-Palm fluxes $\mathcal{E} \mathcal{P}$ (thin solid), dissipation $\mathcal{D}$ (thick solid), prescribed forcing $\mathcal{F}$ (dashed), latent heating $\mathcal{F}^{\text {LH }}$ (dotted), and sensible heating $\mathcal{F}^{\mathrm{SH}}$ (dash-dotted). The short, broad arrow marks the position of the maximum westerly zonal wind at $200 \mathrm{hPa}$, while the long, filled arrow marks the maximum of the standard deviation of the 500-hPa streamfunction.

$650 \mathrm{hPa}$ (Fig. 2f) is maximum just north of the storm track, between $40^{\circ}$ and $60^{\circ} \mathrm{N}$, and it is thus decorrelated from the moisture maximum.

In fact, the humidity is advected from low to high latitudes by synoptic systems and condensation occurs, in this model, mainly in the extratropics. Moreover, condensation is not spatially well correlated with the mean evaporation: it is located, rather, at the same latitudes as the secondary maximum of the standard deviation of the evaporation. We observe the same pattern for the condensation at the $350-\mathrm{hPa}$ level, but with lower amplitude (not shown). The surface sensible heat flux (not shown) increases monotonically from a near-zero value at the equator to a value of $40 \mathrm{~W} \mathrm{~m}^{-2}$ at the pole.

\section{c. The atmospheric jet}

As in LLR11, we propose to isolate the role of the mechanisms that maintain the atmospheric jet. Using the definition of PV and the PV inversion principle, we can obtain the tendency equation for the zonal mean zonal velocity $\left\{u_{i}\right\}$ from Eq. (1):

$$
\frac{\partial\left\{u_{i}\right\}}{\partial t}=+\mathcal{E} \mathcal{P}_{i}+\mathcal{D}_{i}+\mathcal{F}_{i}+\mathcal{F}_{i}^{\mathrm{LH}}+\mathcal{F}_{i}^{\mathrm{SH}} .
$$

The term $\mathcal{E P}$ stands for the effect of the eddies through Eliassen-Palm fluxes [related to $-J\left(\psi_{i}, q_{i}\right)$ in Eq. (1)] on the atmospheric jet. The term $\mathcal{D}$ is related to dissipation $\left[-D\left(\psi_{i}\right)\right]$ while $\mathcal{F}$ is related to the prescribed forcing $\left[S_{i}\right.$ given in Eq. (3)]. The effect of sensible and latent heating on the jet is represented by terms $\mathcal{F}^{\mathrm{SH}}$ and $\mathcal{F}^{\mathrm{LH}}$ (associated with $S_{i}^{\mathrm{SH}}$ and $S_{i}^{\mathrm{LH}}$; see the appendix). The different terms in Eq. (10) allow one to quantify the direct effects of each process on the wind field, while the indirect effect would be more delicate to diagnose. For instance, sensible heating can affect the energy of the eddies, indirectly modulating the Eliassen-Palm fluxes.

Figure 4 displays the temporally and zonally averaged terms on the right-hand side of Eq. (10). In this figure, we indicate the maximum of the westerly wind with short, broad arrows, while the long, filled arrows mark the position of the maximum of $\psi_{500}^{\text {rms }}$. At the upper level (Fig. 3a), the zonal wind maximum is at a low latitude, near $30^{\circ} \mathrm{N}$, and is thus the signature of the STJ. At the lower level ( $800 \mathrm{hPa}$; Fig. 3c), the zonal wind maximum is located farther north, at $48^{\circ} \mathrm{N}$, and corresponds there to a barotropic, eddy-driven PFJ.

The prescribed thermal forcing related to the Hadley cell produces, at $200 \mathrm{hPa}$ (dashed curve in Fig. 4a), a maximum in wind tendency at $32^{\circ} \mathrm{N}$. This corresponds roughly to the latitude of the zonal wind maximum (Fig. 3a). The Eliassen-Palm flux acts to displace the jet poleward since it decelerates the jet at low latitudes (below $23^{\circ} \mathrm{N}$ ) and accelerates it poleward (solid curve). The latent heating (dotted curve) is smaller in amplitude than the Eliassen-Palm flux and acts to decelerate the westerlies in the subtropics and accelerate the subpolar westerlies.

The combined effects of these two terms explain why there is a broad region of high jet intensity (Fig. 2a). The sensible heat exerts virtually no direct impact on the upper-level zonal wind (dash-dotted line). The dissipation (bold solid curve) decelerates the zonal jet everywhere and it is mainly controlled by the thermal relaxation term; it is thus well correlated in position with the jet and anticorrelated with it in intensity (cf. Fig. 3a).

As noted earlier, the low-level jet in the subtropics is easterly (Fig. 3c) because of the prescribed thermal 
forcing term related to the Hadley cell (dashed curve in Fig. 4b). The eddies give rise to Eliassen-Palm fluxes that are responsible for an acceleration of this jet south of $20^{\circ} \mathrm{N}$. North of $45^{\circ} \mathrm{N}$, a westerly jet (Fig. 3a) is maintained by the eddy terms. Comparison with Fig. 4a shows that the Eliassen-Palm fluxes generate a barotropic subpolar jet (Holton 1992; Held 2000).

The latent heating effect on the $800-\mathrm{hPa}$ zonal wind is opposite to that exerted on the $200-\mathrm{hPa}$ wind, with westerly and easterly accelerations equatorward and poleward of $50^{\circ} \mathrm{N}$, respectively. The surface sensible heating tends to create a broad westerly jet poleward of $30^{\circ} \mathrm{N}$. The fact that the sensible heating is not localized in latitude is due to the smooth SST gradient. The surface sensible heating effect, though, is less pronounced compared to the other components of the forcing in Eq. (10). We should keep in mind, however, that the surface sensible heating exerts additional indirect effects on the westerly jet by modulating the eddy activity.

\section{Dependence on the SST gradient}

To quantify the effects of SST gradients on atmospheric dynamics, we construct a localized SST front that extends over $120^{\circ}$ of longitude. We call this band of longitude the frontal domain and keep it fixed for the rest of the study. Given the azimuthal symmetry of our aquaplanet configuration, we let this band arbitrarily be $120^{\circ} \mathrm{E}-120^{\circ} \mathrm{W}$.

Between $130^{\circ} \mathrm{E}$ and $130^{\circ} \mathrm{W}$, we add the "frontal function" $T_{\text {fr }}(\phi)$ to the SST profile $T_{\text {ref }}(\phi)$ in Eq. (9):

$$
T_{\mathrm{fr}}(\phi)=-\mu \alpha\left(\phi-\phi_{1}\right) e^{-\left|\alpha\left(\phi-\phi_{1}\right)\right|^{\beta / \beta} / \beta} ;
$$

here $\phi_{1}, \mu, \alpha$, and $\beta$ are parameters chosen to adjust the position, strength, and width of the front. The constant $e$ is $e=\exp (1)$. Between $0^{\circ}$ and $120^{\circ} \mathrm{E}$ and between $120^{\circ} \mathrm{W}$ and $0^{\circ}$, the SST field is given by Eq. (9), while near the two edges of the frontal domain the SST field is smoothly interpolated over the $10^{\circ}$ intervals $120^{\circ}-130^{\circ} \mathrm{E}$ and $130^{\circ}-120^{\circ} \mathrm{W}$, respectively.

To define the meridional extent of the front, we first introduce the intersection points between the tangent at the inflection points and the axis $T_{\mathrm{fr}}=0$. The meridional extent $E_{\phi}$ is thus the distance between these two intersection points, which lie on either side of $\phi_{1}$, and it depends only on $\alpha$ and $\beta$ :

$$
E_{\phi}(\alpha, \beta)=\frac{(e+e \beta)^{1+1 / \beta}}{\alpha \beta e} .
$$

We define the strength $s_{\phi_{1}}$ of the front to be the gradient of the function $T_{\text {ref }}(\phi)+T_{\text {fr }}(\phi)$ at the latitude $\phi_{1}$. The latitude of the SST front $\phi_{1}^{\prime}$ is given by the maximum value of the meridional derivative of $T_{\text {ref }}(\phi)+T_{\mathrm{fr}}(\phi)$. It turns out that $\phi_{1}^{\prime}-\phi_{1}$ is smaller than $1^{\circ}$ when the frontal strength is larger than $1 \mathrm{~K}(100 \mathrm{~km})^{-1}$ and it is less than $5^{\circ}$ for the entire range of parameters used herein; hence we omit the $(\cdot)^{\prime}$ in the following.

Note that the function $T_{\mathrm{fr}}(\phi)$ does not preserve the mean value of the SST field, especially when $\phi_{1}$ is set to a high or a low latitude. Moreover, SST values above $T_{\mathrm{m}}$ are readjusted to equal $T_{m}$, while values below $T_{0}$ are readjusted to equal $T_{0}$. We checked that, for all the experiments reported herein, the mean SST does not differ by more than $2 \mathrm{~K}$ compared to the control run. Since the temperatures of the equator and of the pole remain fixed, the results of Caballero and Langen (2005) indicate that a variation of $2 \mathrm{~K}$ in mean SST is not so large as to modify the dynamics significantly (see also Kodama and Iwasaki 2009).

Before performing a more systematic sensitivity study for different positions and strengths of the front, we analyze in detail at first three frontal configurations that yield representative types of model behavior.

\section{a. Three case studies}

The first experiment (hereafter Exp. 1), corresponds to $\phi_{1}=25^{\circ} \mathrm{N}, \mu=7.5 \mathrm{~K}, \alpha=13.3 \mathrm{rad}^{-1}$, and $\beta=1.4$; in the second (Exp. 2), we choose $\phi_{1}=40^{\circ} \mathrm{N}, \mu=7.5 \mathrm{~K}$, $\alpha=13.3 \mathrm{rad}^{-1}$, and $\beta=1.4$; and in the third (Exp. 3), we have $\phi_{1}=55^{\circ} \mathrm{N}, \mu=9.0 \mathrm{~K}, \alpha=22.2 \mathrm{rad}^{-1}$, and $\beta=1.0$. The meridional SST profiles-at longitude $180^{\circ}$ (i.e., in the middle of the frontal domain) - of these three experiments are plotted in Fig. 1. All three experiments correspond to fronts of comparable strength $s_{\phi_{1}}$-of 2.2, 2.1 , and $2.5 \mathrm{~K}(100 \mathrm{~km})^{-1}$, respectively-and thus differ mainly by their position. The meridional extent of all these fronts, given by Eq. (12), is equal to $30^{\circ}$ of latitude, but because of the restriction $T_{0}<T<T_{m}$, the extent of the front diminishes when $\phi_{1}$ is set to a low or a high latitude (cf. Fig. 1). The mean SST restricted to the frontal domain is equal to $286.9 \mathrm{~K}$ for Exp. 1, 288.3 $\mathrm{K}$ for Exp. 2, and 289.3 K for Exp. 3.

We chose SST fronts that are strong and wide in order to render the phenomena of interest as clearly visible as possible, while still staying as realistic as possible. This choice allows us to study the influence of fronts of similar shapes but centered at different latitudes. For each experiment, as for the control run, we analyze the time-mean field of a 10 000-day model run, after a spinup of 2000 days.

In Fig. 5a, we plot the zonal upper-level wind obtained in each of the three experiments. The zonal wind averaged in the frontal domain at different altitudes is shown in Fig. 3. Outside the frontal domain, a westerly jet is present between $20^{\circ}$ and $50^{\circ} \mathrm{N}$, as in the control run, and 

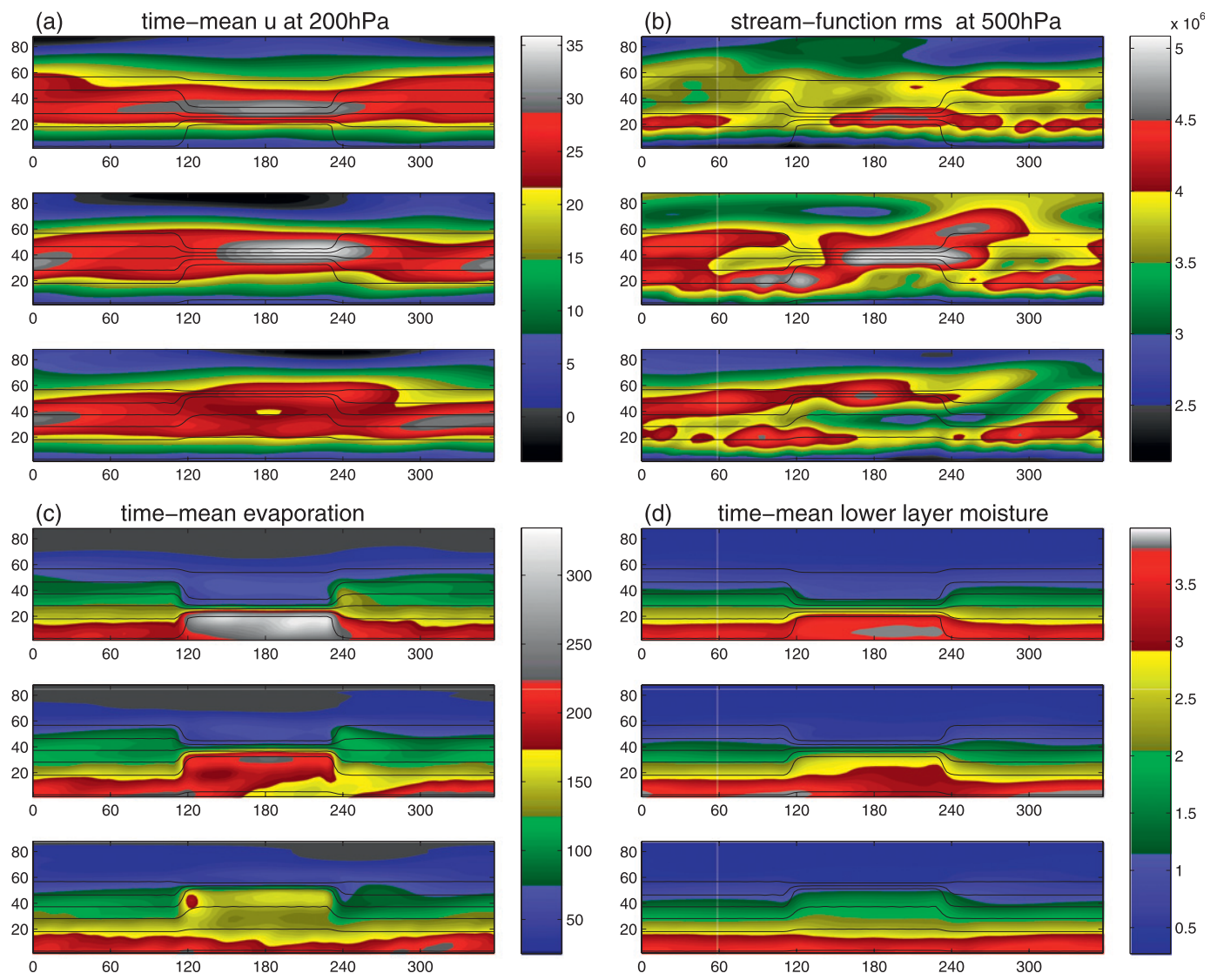

(e) time-mean lower layer condensation

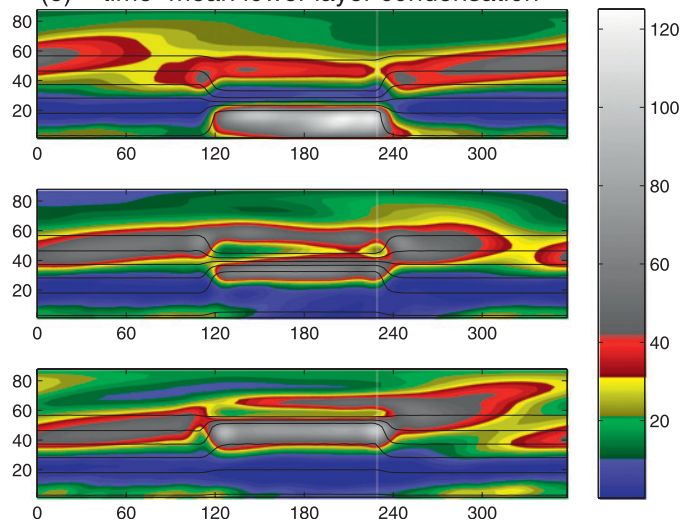

FIG. 5. As in Fig. 2, but for (top) Exp. 1, (middle) Exp. 2, and (bottom) Exp. 3. The color palette is as in the control run in Fig. 2, over the blue-green-yellow-red range; higher values are plotted from gray to white, while lower values are plotted from black to gray.

its intensity increases when the SST front moves northward from being centered at $25^{\circ} \mathrm{N}$ in Exp. 1 to $55^{\circ} \mathrm{N}$ in Exp. 3 (Fig. 5a). In the frontal domain, the 200-hPa jet of Exp. 1 has its axis around $30^{\circ} \mathrm{N}$ (i.e., on the poleward side of the SST front; Fig. 3a). Moreover, it is zonally elongated in the middle of the frontal domain (Fig. 5a).

In Exp. 2, the jet is shifted poleward, around $45^{\circ} \mathrm{N}$, along with the SST front (Fig. 3a), and it intensifies downstream, while passing through the frontal region, up to a speed of $35 \mathrm{~m} \mathrm{~s}^{-1}$ (see the middle panel of Fig. 5a). We note that Brayshaw et al. (2008) observed the same intensification of the jet when the SST gradient is modified in their primitive equation experiments (see their Fig. 8).

In Exp. 3, when the SST front is centered at an even higher latitude, the jet separates into two branches and two distinct zonal-wind maxima arise in the frontal domain (see 
Fig. 3a and the bottom panel of Fig. 5a). The primary branch of the westerly jet, at $25^{\circ} \mathrm{N}$, has a speed of $28 \mathrm{~m} \mathrm{~s}^{-1}$ and its secondary branch, at $60^{\circ} \mathrm{N}$, has a speed of $26 \mathrm{~m} \mathrm{~s}^{-1}$. This double-jet structure is reminiscent of the one in Son and Lee (2005) and can be explained in terms of the appearance of a PFJ maintained by baroclinic eddies and of an STJ maintained by the thermal forcing.

As we will see in next section, the strength of the PFJ varies with the gradient of the SST front. At the different vertical levels, a comparison of Figs. $3 b$ and $3 c$ with Fig. 3a also shows the meridional shift and intensification of the jet when the SST front is moved poleward. These differences between the results of the three experiments confirm that the SST front does have an influence on the barotropic eddy driven jet.

The standard deviation of the streamfunction at $500 \mathrm{hPa}$ is shown in Fig. $5 \mathrm{~b}$; it has to be compared to the same field in the control run (Fig. 2c). In all three experiments, the storm track is affected by the presence of the front, but the response differs from one experiment to another. In each case, the storm track activity is largest at the axial latitude of the SST front over the frontal domain.

In Exp. 2 and Exp. 3, the presence of the front affects the storm track outside the frontal domain as well: the intensity increases upstream as well, near $50^{\circ} \mathrm{N}$. In Exp. 1 and Exp. 2, a secondary eddy-activity maximum is present to the east and north of the frontal domain. Brayshaw et al. (2008) also observed this secondary maximum for a simulation performed with an SST anomaly that gives rise to a midlatitude SST front. If the SST front is centered too far poleward or equatorward, though, the eddies are less intense compared to the case in which the eddies are collocated with the midlatitude jet and SST front (see middle panel of Fig. 5b).

In all three experiments, the evaporation pattern is strongly affected by the presence of the front (Fig. 5c). Indeed, at the frontal latitude, we observe a strong meridional gradient of evaporation. The evaporation $E$ is maximum in Exp. 1 and reaches a value of $320 \mathrm{~cm} \mathrm{yr}^{-1}$, about twice as large as in the control run; this absolute maximum decreases in Exp. 2 and Exp. 3. The larger value compared to the control run is due to the presence of high SST values at low latitudes (see Fig. 1). The evaporation maximum remains anchored on the equatorward side of the front: in Exp. 1 and Exp. 2, we observe an attenuation of the evaporation on the poleward side of the front as well. The mean evaporation in the frontal domain is roughly the same in all three experiments and reaches $104 \mathrm{~cm} \mathrm{yr}^{-1}$. The standard deviation of the evaporation (not shown) has exactly the same shape as the mean in all three cases, showing that the variability of $E$ is well correlated with its intensity.
Of course, these changes in evaporation affect the amount of water present in the atmosphere. As the mean evaporation is about the same in all three cases, it corresponds to an equal quantity of moisture being present in the lower layer of the frontal domain, namely a mean value about $1.5 \mathrm{~g} \mathrm{~kg}^{-1}$ for all experiments. However, the location of the maximum humidity differs from one experiment to another. The mean moisture in the three cases is shown in Fig. 5d. The moisture maximum is collocated with the spatial evaporation pattern in all three experiments. The relative humidity in the lower layer (not shown) displays a maximum in the storm-track region, thus suggesting poleward and downstream advection of moisture by baroclinic eddies. In the upper layer (not shown), the mean moisture pattern is the same as in the lower layer, but it has a lower amplitude.

Concerning condensation, Fig. 5e exhibits two maxima over the meridional extent of the frontal domain. The first one is due to the high evaporation rates south of the SST front. The secondary condensation band is located northward of the SST front and is induced by synoptic baroclinic eddies. This secondary condensation band, which is located around $50^{\circ} \mathrm{N}$ in the control run, is shifted poleward in Exp. 2 and Exp. 3. The concentration of condensation is consistent with the strong synoptic activity, as measured by $\psi^{\text {rms }}$, thus confirming the causal link between the rain and the baroclinic eddies. Condensation is also considerably intensified outside the frontal domain.

For all three experiments, we evaluate the contributions to the zonal-wind tendencies as we did for the control run. Only the diagnostics for the upper-level wind in the three experiments are shown in Fig. 6. We compare each of these figures with the diagnostics of the control run (Fig. 4a). The differences between Exp. 1 (Fig. 6a) and the control run appear to be quite small. Still, when the SST front is located at $25^{\circ} \mathrm{N}$, the latent heating (dotted curve) decelerates the jet less at midlatitudes (between $24^{\circ}$ and $45^{\circ} \mathrm{N}$ ) than in the control run. The effect of the surface sensible heating (dash-dotted) is still small compared to the others terms, but it is responsible for the jet's intensification at the exact latitude of the SST front. This term also tends to decelerate the jet at higher latitudes. The combination of these two effects leads to the jet's acceleration near $35^{\circ} \mathrm{N}$ (Fig. 3a).

In Exp. 2 (Fig. 6b), the surface sensible heat flux tends again to accelerate the jet at the exact position of the SST front, while the latent heat tendency decelerates the jet below $40^{\circ} \mathrm{N}$ and accelerates it above $55^{\circ} \mathrm{N}$. Its effect is quite limited in the band $40^{\circ}-55^{\circ} \mathrm{N}$, which explains in part the jet's amplification there. At the same time, the effect of the nonlinear advection terms (thin solid) is to displace the jet farther poleward, toward $55^{\circ} \mathrm{N}$, than in 

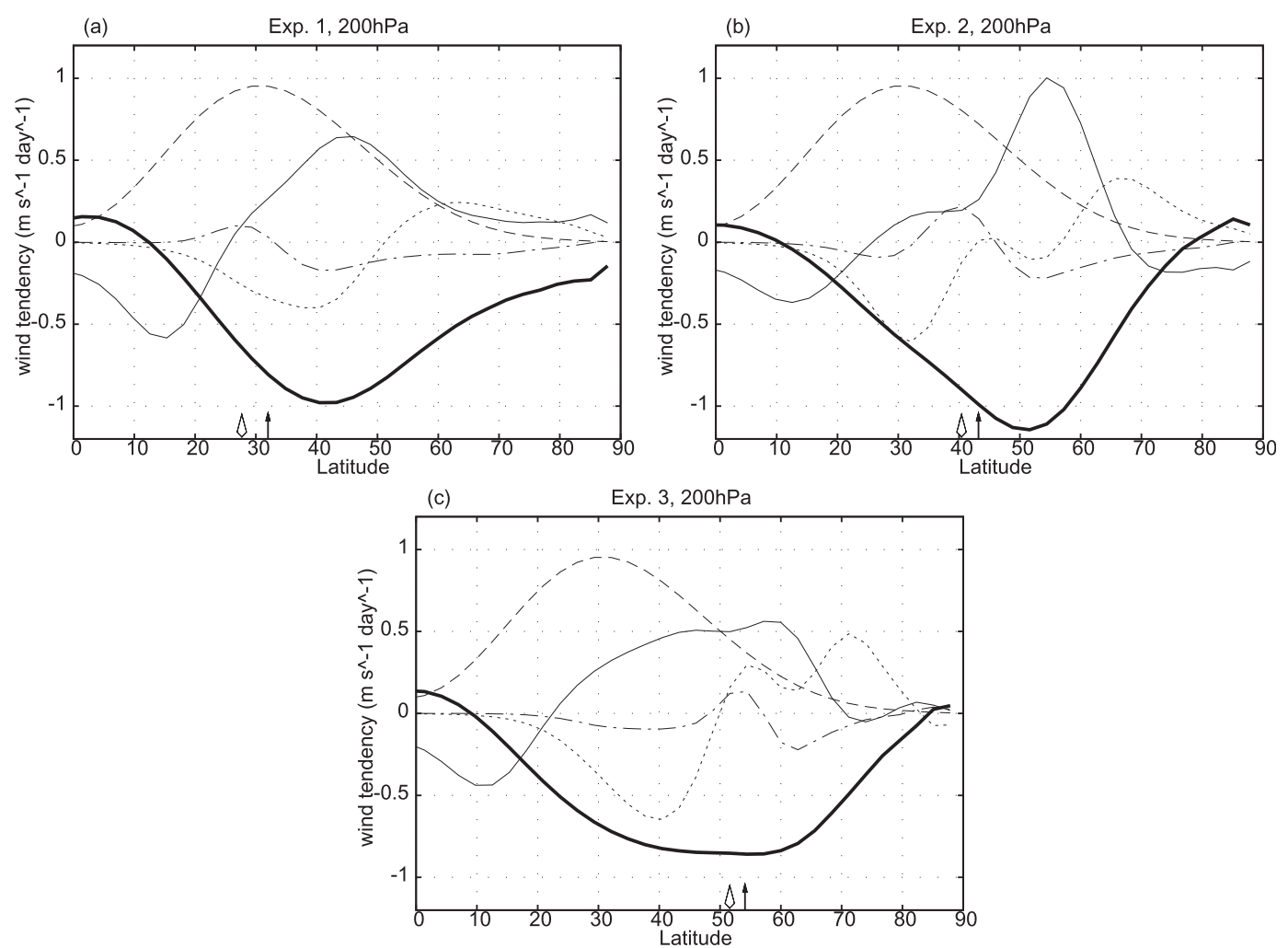

FIG. 6. As in Fig. 4a, but for (a) Exp. 1, (b) Exp. 2, and (c) Exp. 3. The spatial averaging is performed only over the frontal domain $\left(130^{\circ} \mathrm{E}-130^{\circ} \mathrm{W}\right)$; see text for details. The meridional position of the SST front is respectively at $25^{\circ}, 40^{\circ}$, and $55^{\circ} \mathrm{N}$ in Exp. 1, Exp. 2, and Exp. 3 (see also Fig. 1).

the control run. Once again, these tendency considerations are in good agreement with the climatological position of the upper-level atmospheric jet in this experiment (see Fig. 3a). In Exp. 3 (Fig. 6c) -as in Exp. 1 and Exp. 2-the surface sensible heat term forces the jet most effectively at the latitude of the SST front, but still only moderately. In this case, the nonlinear term accelerates the jet near $60^{\circ} \mathrm{N}$, while the low-latitude deceleration by this term is smaller than in the other two cases. The effect of the latent heating is to accelerate the jet at latitudes higher than $50^{\circ} \mathrm{N}$. Comparing Figs. $5 \mathrm{a}$ and $6 \mathrm{c}$ shows that the local minimum of the zonal wind corresponds to the maximum deceleration by latent heat fluxes.

\section{b. Position and strength of the SST front}

These three experiments can be put in a more general context by varying both the position and the strength of the SST front. To this end, we use the frontal function $T_{\text {fr }}\left(\phi ; \mu, \phi_{1}, \alpha, \beta\right)$ of Eq. (11) to construct a family of fronts of different strengths and centered at different latitudes $\phi_{1}$. As a first step, we choose to keep $E_{\phi}$ fixed at $30^{\circ}$ for all simulations, as in the previous subsection. We also choose the best parameters $(\mu, \alpha, \beta)$ as the SST decays monotonically with latitude. We conducted more than 50 experiments to cover a large part of the model's parameter space with different spatial resolutions (most of the graphs have been created with 35 simulations). We present mainly the zonal mean over the frontal domain of several fields.

Figure 7 is a summary of the experiments performed for several prescribed SST fronts. In each panel, the abscissa represents the effective strength of the SST front while the ordinate represents the latitude $\phi_{1}$ of the front, for each experiment. The three specific frontal configurations studied in the previous subsection are plotted as filled squares in each panel of Fig. 7.

Figure $7 \mathrm{a}$ represents the maximum speed of the zonal wind in the frontal domain, averaged between $120^{\circ}$ and $240^{\circ} \mathrm{E}$. The speed attained by the atmospheric jet in these experiments depends on both the maximal SST gradient $s_{\phi_{1}}$ and the latitude at which it occurs. For small values of the SST gradient, $s_{\phi_{1}} \leq 1.0 \mathrm{~K}(100 \mathrm{~km})^{-1}$, the maximal jet speed is not much larger than in the control run (cf. Fig. 3a). For an SST front located between $25^{\circ}$ and $50^{\circ} \mathrm{N}$, the jet intensifies with $s_{\phi_{1}}$, but when $\phi_{1}>55^{\circ} \mathrm{N}$ its strength no longer depends much on $s_{\phi}$. The overall jet speed maxima occur for $\phi_{1} \simeq 38^{\circ} \mathrm{N}$ and 

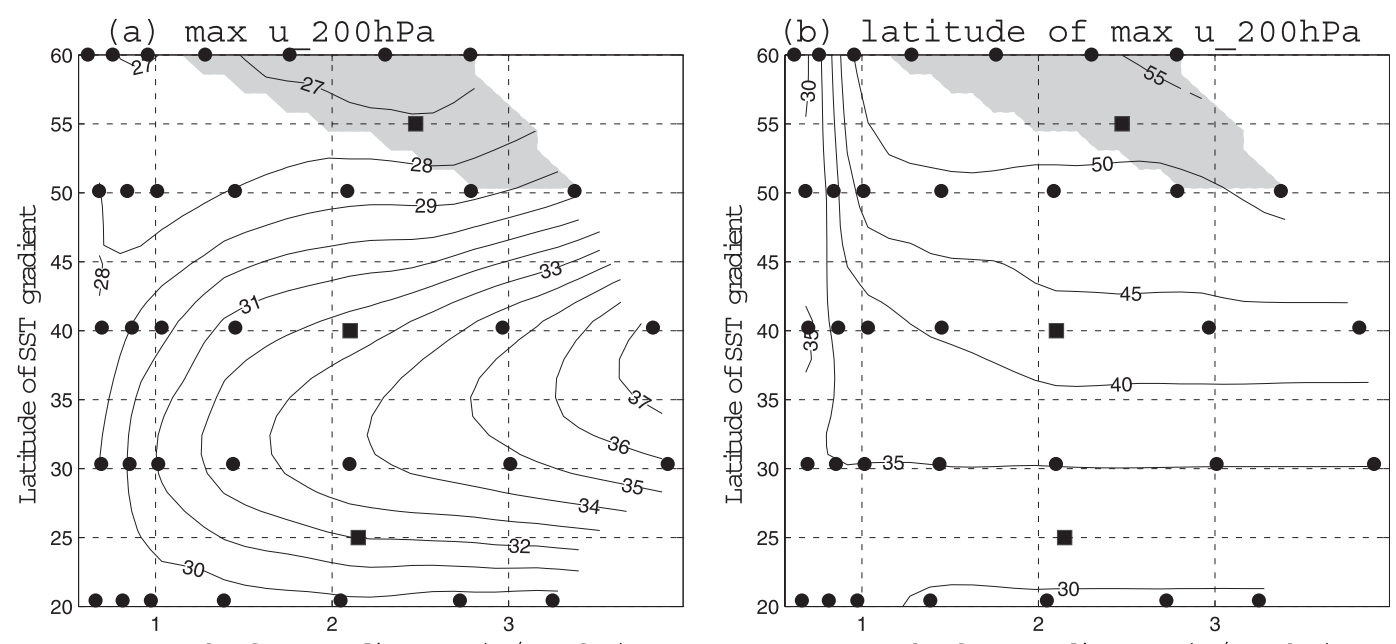

Strength of SST gradient (K/100 km)
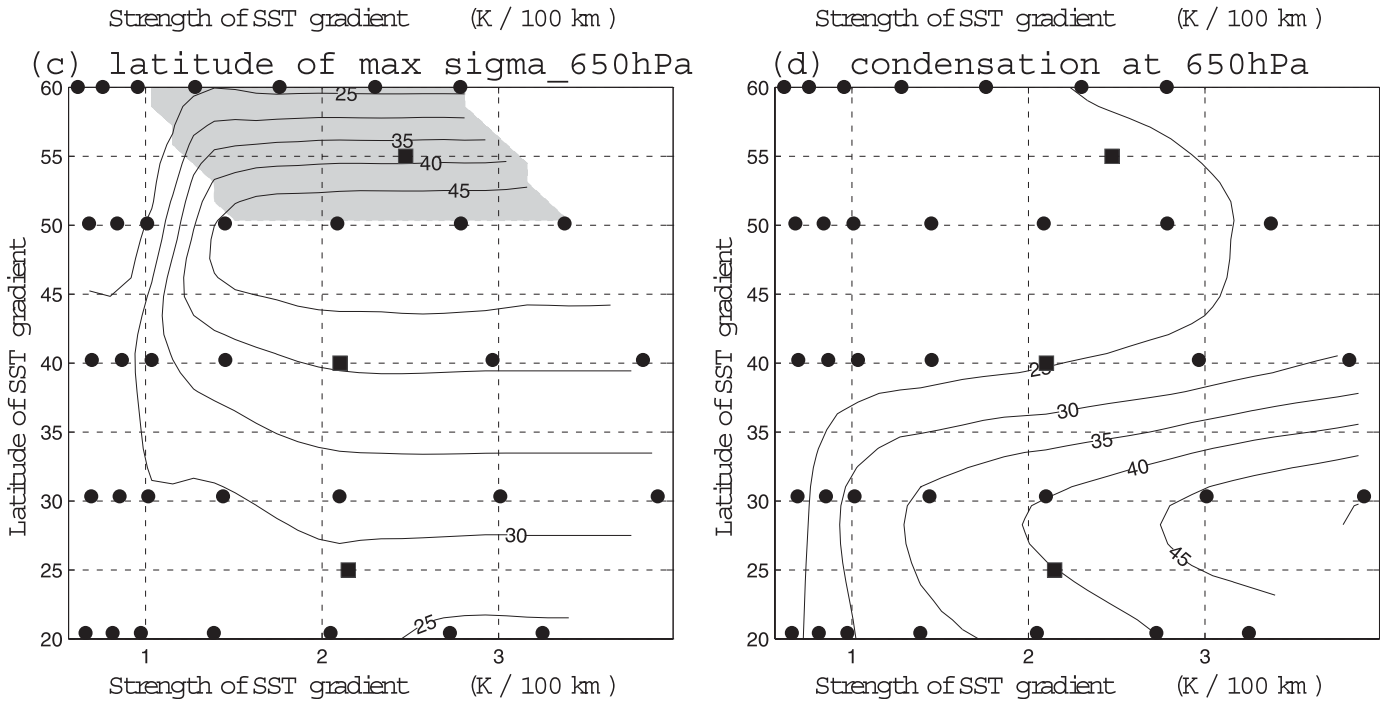

FIG. 7. Mean fields and isopleths of maxima computed in the frontal region $\left(120^{\circ} \mathrm{E}-120^{\circ} \mathrm{W}\right):(a) \max \left(\overline{u_{200}}\right)$ (contours; $\left.\mathrm{m} \mathrm{s}^{-1}\right)$, (b) latitude $\phi_{u_{\max }}$ of $\max \left(\bar{u}_{200}\right)$ and (c) latitude $\phi_{\sigma_{\max }}$ of the baroclinicity maximum $\max \left(\sigma_{650}\right)$ $\left({ }^{\circ} \mathrm{N}\right)$, and (d) averaged condensation $\overline{P_{650}}\left(\mathrm{~cm} \mathrm{yr}^{-1}\right)$. The shaded area in (a) and (b) corresponds to the parameter domain over which a secondary jet is present. In (c) it corresponds to the presence of a secondary region of maximum baroclinicity. The filled circles mark the position of all the experiments that we have conducted, while the filled squares mark the position of the three experiments discussed in section $3 \mathrm{a}$.

$s_{\phi_{1}}>2.5 \mathrm{~K}(100 \mathrm{~km})^{-1}$. The local maximum when $\phi_{1}$ increases from $25^{\circ}$ to $50^{\circ} \mathrm{N}$, at fixed $s_{\phi_{1}}$ (Fig. $7 \mathrm{a}$ ), and the associated ridge suggest the presence of a resonance mechanism and will be further discussed below. Here, resonance is to be taken in a broad sense that the sensitivity to SST gradient is maximum when the latitude of the SST front is close to the latitude of the upper-level jet.

The shaded area in Fig. 7a delimits the zone where a secondary maximum is present in the zonal wind's meridional profile. This secondary jet is located around $25^{\circ} \mathrm{N}$, as can be seen in Fig. 3a for Exp. 3. This STJ attains speeds that are comparable to the subpolar jet (around $15 \mathrm{~m} \mathrm{~s}^{-1}$ ) and it is present only for $\phi_{1}>50^{\circ} \mathrm{N}$ and for a sufficiently strong SST front. The core speed of this secondary jet increases with $\phi_{1}$, while that of the eddy-driven jet decreases.

The latitude of the maximal speed of the jet at $200 \mathrm{hPa}$ $\phi_{u_{\max }}$ is plotted in Fig. 7b. We see that the position of this maximum depends mostly on the latitude, but not the strength, of the front. For $s_{\phi_{1}}$ smaller than $1 \mathrm{~K}(100 \mathrm{~km})^{-1}$ though, the jet is rapidly restored to its control-run position, with decreasing $s_{\phi_{1}}$. For $30^{\circ}<\phi_{1}<50^{\circ} \mathrm{N}$, the jet is anchored just slightly poleward of the position of the front, while for $\phi_{1}>50^{\circ} \mathrm{N}$, the PFJ is accompanied by a secondary jet, as seen already in the bottom panel of Fig. 5a, for Exp. 3. This secondary maximum around $25^{\circ} \mathrm{N}$ corresponds to the STJ maintained by the prescribed thermal forcing. 
The parameter domain for which we observe a clear separation between the PFJ and the STJ is shaded in this panel as well: we note that the PFJ's latitude stays roughly comparable to $\phi_{1}$ (see also Son and Lee 2005). These authors observe a single-jet or a double-jet pattern of the zonal winds, depending on the imposed tropical heating and high-latitude cooling. Here the single- or double-jet structure arises depending first on the location and then on the strength of the SST front.

To see if the "oceanic baroclinic adjustment" proposed by Nakamura et al. $(2004,2008)$ is at work in our QG3H, we examine the lower-layer baroclinicity $\sigma_{650}$, as defined by Hoskins and Valdes (1990):

$$
\sigma_{650}=\frac{0.31}{\lambda_{650}}\left(u_{500}-u_{800}\right) .
$$

As shown in Fig. 7c, when the SST front is strong enough, the latitude of the maximum of lower-layer baroclinicity $\phi_{\sigma_{\max }}$ increases with the latitude of the SST front, up to $45^{\max } \mathrm{N}$. The amplitude of the lower-layer baroclinicity is weakly dependent on both the latitude and the strength of the SST front (not shown). Furthermore, as for the upper-level jet in the previous two panels, a secondary maximum of baroclinicity is present south of the main maximum when $\phi_{1}>50^{\circ} \mathrm{N}$ (represented by the shaded area in Fig. 7c), although its intensity is much lower (not shown).

Still, the baroclinically most active zone does not move too far poleward and stays between $25^{\circ}$ and $45^{\circ} \mathrm{N}$ for all the frontal configurations explored. This shows that the "oceanic baroclinic adjustment" is not at work in our simulation. In fact, the atmospheric forcing, as given by Eq. (3), only constrains the lower-layer baroclinicity around $35^{\circ} \mathrm{N}$, as seen in Fig. 7c. By comparing Figs. 7c and $7 \mathrm{a}$, one notes that when the SST front is close to the latitude of the baroclinicity maximum, it is the upper-level jet's speed that is the most sensitive to the strength of the SST front.

Figure $7 \mathrm{~d}$ shows the dependence of the large-scale condensation, averaged over the frontal domain, to the latitude and strength of the SST front. In fact, we note that higher $s_{\phi_{1}}$ values do not increase the mean evaporative flux or the mean amount of water vapor present in the atmosphere (not shown). The mean condensation at $650 \mathrm{hPa}$, though, does increase when $s_{\phi_{1}}$ increases, especially for $\phi_{1} \leq 40^{\circ} \mathrm{N}$, and so does the maximum condensation (not shown).

\section{c. Effect of the surface sensible and latent heat fluxes}

We have performed additional simulations to help us quantify the relative effects of the surface latent and sensible heat fluxes on the strength and position of the jet. In Fig. 8, the same results as in Figs. 7a,b are plotted, but they correspond now to the model being integrated first without moist processes (top panels) and then without surface sensible heat flux (bottom panels), in order to separate the two effects.

Comparing the two pairs of panels, Figs. $8 \mathrm{a}, \mathrm{b}$ and Figs. 8c,d, with each other and with Figs. 7a,b shows that both the surface sensible heat fluxes and the moist processes induced by surface evaporation play a role in the intensification of the upper-level eddy-driven jet. We note that in the experiment where the surface sensible heat flux is retained (Fig. 8a), the eddy-driven jet is still accelerated most strongly for $\phi_{1} \simeq 32^{\circ} \mathrm{N}$ (i.e., when it is closest to the SST front; cf. Fig. 8b). This acceleration is only by $4 \mathrm{~m} \mathrm{~s}^{-1}$ —compared to $8 \mathrm{~m} \mathrm{~s}^{-1}$ when both surface sensible and latent heating are presentas $s_{\phi_{1}}$ increases from 0.5 to $4 \mathrm{~K}(100 \mathrm{~km})^{-1}$. Hotta and Nakamura (2011) already reported the acceleration of westerlies in the storm-track region in response to surface sensible heating.

For the simulations with latent heating, and no surface sensible heat flux, the eddy-driven jet also intensifies as the strength of the SST front increases (Fig. 8c) but the intensification is maximum at a considerably higher latitude, $\phi_{1}=40^{\circ} \mathrm{N}$, than in Figs. 7a and 8a, based on the experiments with surface sensible heat flux. The westerly acceleration simulated under the SST gradient between 0.5 and $4 \mathrm{~K}(100 \mathrm{~km})^{-1}$ corresponds to just a little more than half the acceleration seen in Fig. 7a.

Comparing Fig. $8 \mathrm{~b}$ with Fig. 8d, we see that in the experiments with latent heating, the eddy-driven jet shifts significantly related to its position in the control run (see Fig. 3a), while it remains close to the meridional position of the control run in the runs in which only surface sensible heating is present. This means that the surface sensible heating alone cannot be responsible for the anchoring of the eddy-driven jet above the SST front. On the contrary, moist processes and the localization of the evaporation pattern do play a key role in the positioning of the jet. Moreover, it is only in the simulations with latent heating (i.e., Figs. 8a,b) that the double-jet pattern arises. The secondary jet in this case is present even for fairly weak fronts, even for $s_{\phi_{1}}<0.5 \mathrm{~K}(100 \mathrm{~km})^{-1}$. Its latitude and strength are similar to those observed for the full model.

It follows that the intensification of the jet observed in Figs. 7a,b is due to both sensible and latent heat fluxes at the surface, while moist processes control the meridional shifting of the jet. In addition, the storm track reacts to diabatic heating, both sensible and latent. Hoskins and Valdes (1990) have shown that this diabatic heating was necessary for the maintenance of the storm tracks, as it is a source of strong midtropospheric baroclinicity. 

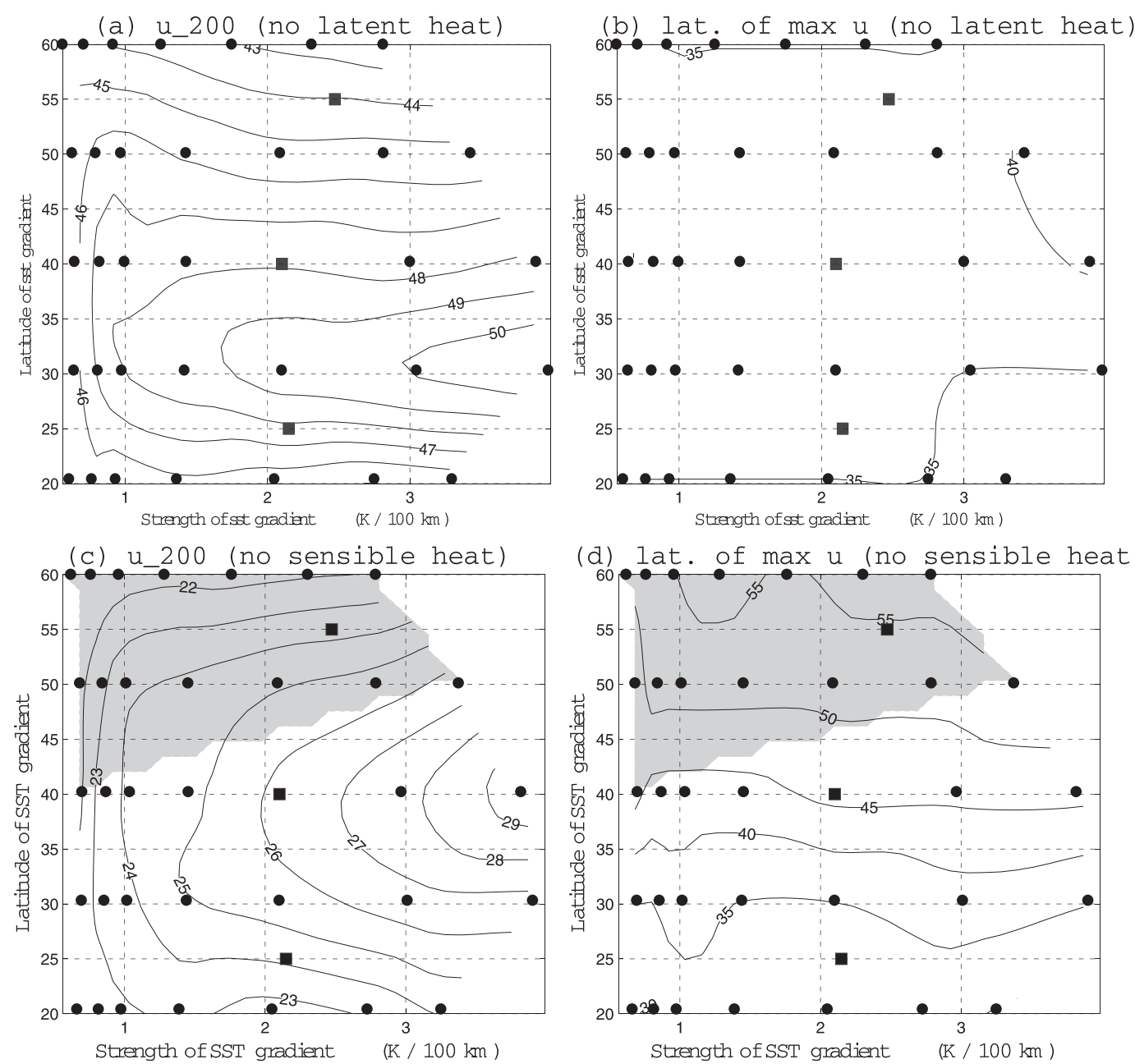

FIG. 8. Jet properties for simulations (a),(b) with no latent heating and (b),(d) with latent heating. (a),(c) Maximum zonal velocity; (b),(d) latitude of the $200-\mathrm{hPa}$ jet. Abscissa is the strength of the SST front $\left[\mathrm{K}(100 \mathrm{~km})^{-1}\right]$.

\section{Concluding remarks}

We studied the effect of a large-scale SST front on the atmospheric jet and storm track by using an idealized QG model forced with different SST patterns. Both sensible heat flux and moist processes are included in the aquaplanet configuration of our QG3H model, and the resulting mean fields, as well as their standard deviations, are reasonable for such a configuration and the model's T42 resolution. We showed that both the position and the strength of the SST front can modify the intensity, as well as the position, of the upper-level atmospheric jet. Using a decomposition of the different forcing terms, we showed that the surface sensible heat flux modestly acts to reinforce the upper-level jet at the exact position of the SST front, while the eddies (through Eliassen-Palm fluxes) and the latent heat release act to displace the jet northward.
In this QG3H model, we find that, for a strong enough SST front that lies at rather high latitudes, poleward of $40^{\circ} \mathrm{N}$, a clear separation results between a polar-front jet (PFJ) and the more prevalent subtropical jet (STJ). Other explanations have been provided for a bimodal distribution of zonal velocities, as well as for jet splitting, depending on the region in the model's parameter space. Some of the explanations were related to the presence of zonal inhomogeneities in the lower boundary conditions (Kravtsov et al. 2005, 2006) and others to wave-mean flow interaction (Koo and Ghil 2002; Koo et al. 2002), to interactions with the stratosphere (Bordi et al. 2009), or to feedbacks among the SST field, the storm track, and annular modes (Nakamura et al. 2008).

It is conceivable that some interaction between these various causes might contribute to the bimodality that is often observed in SH flows (Trenberth 1991; Nakamura and Shimpo 2004). We note that jet splitting observed 
south of Australia during June-August (JJA) occurs with a subpolar jet that lies $5^{\circ}$ poleward of the strong SST front, which has a $3.4 \mathrm{~K}(100 \mathrm{~km})^{-1}$ gradient, and is thus in agreement with our model results. The weak storm track that is observed in nature may be due to an SST front that lies too far poleward. This conjecture is supported by our model results, since its eddy activity decays when the latitude of the SST front is too far poleward.

To better understand the roles of the sensible and latent heating, we performed two sets of simulations: one turning off latent heat release and the other one without surface sensible heat flux. It appears that, while the surface sensible heat flux can intensify the jet, it is not able to displace it. On the contrary, latent heating affects both the jet's latitude and its strength. The latitude of the SST front appears to be the most important parameter that controls the amplitude of the response. In fact, when the front is located near $40^{\circ} \mathrm{N}$, the most baroclinically active zone of the atmosphere is enhanced and the SST front amplifies the jet. On the contrary, when the front is located at lower or at higher latitudes, it tends to shift the baroclinic zone that exists for a climatological SST profile and to modify the latitude of the eddy-driven PFJ.

These results highlight the nonlocal nature of water vapor effects, since the water evaporates on the warm side of the SST front and condensates, thus releasing its latent heat, much farther poleward. The subsequent increase of temperature at high latitudes is responsible in part for the jet's displacement due to thermal wind balance. This displacement is further amplified by the nonlinear effects of the Eliassen-Palm fluxes.

The main deficiency of such a QG model lies in the absence of a correct representation of the Hadley cell. The model has weak easterlies in the tropics but, as discussed by Held (2000), it cannot have a meridional circulation near the equator, like primitive equation models. The STJ in our model is therefore entirely forced and has no real variability in the tropics. This is not an issue for our study, since we focused on the response of the midlatitude storm track to midlatitude SST. In another study, Lu et al. (2010) also showed that the tropospheric jet was sensitive to moisture in their primitive equation experiments. The results that we obtain for SST fronts below $30^{\circ} \mathrm{N}$ should be taken, therefore, with a grain of salt.

Furthermore, no coupling between radiative forcing and moist processes or even with the temperature field is accounted for. Interactions of the free atmosphere with the surface through the boundary layer are parameterized only quite crudely, as the surface forcing is introduced in the first model layer. It thus remains to be seen whether this study's main conclusions will hold for more detailed and realistic models.

Still, the results herein do contribute to a better understanding of the effects of sharp SST fronts on the mean and variability of the atmospheric flow above and downstream of these fronts, as recently studied by several authors (Feliks et al. 2004, 2007; Nakamura et al. 2004; Minobe et al. 2008; Brayshaw et al. 2008; Small et al. 2008; Hotta and Nakamura 2011). Further progress will probably require more detailed modeling of the processes in the marine atmospheric boundary layer, as well as fully coupled ocean-atmosphere models with sufficiently high horizontal and vertical resolution.

Acknowledgments. It is a pleasure to thank Henk Dijkstra and Patrice Klein for useful comments on the original version of the paper. The final version has benefitted from detailed comments by David Brayshaw, two anonymous reviewers, and Shigeo Yoden. This work was supported by National Science Foundation Grant DMS-1049253 to MG. GL acknowledges funding from Fondation MAIF through the grant "REVAEE."

\section{APPENDIX}

\section{Diabatic Forcing Terms in the QG3H Model}

\section{a. Conversion of the heating into PV tendency}

The surface sensible heating $S^{\mathrm{SH}}$, as well as the latent heating $S^{\mathrm{LH}}$, can be inserted into the PV equation via the diabatic heating term (Holton 1992, ch. 6). To convert the surface sensible heat flux $E^{\mathrm{SH}}$ from Eq. (4) into diabatic heating at $650 \mathrm{hPa}$, we divide by the mass $\rho \Delta z=$ $\Delta P / g$ of the air being heated, where $g$ is the gravity constant and $\Delta P$ the thickness of the heated layer.

The corresponding terms $S_{j}^{\mathrm{SH}}$ and $S_{j}^{\mathrm{LH}}$ in the PV tendencies have the following form:

$$
\begin{aligned}
S_{1}^{\mathrm{LH}} & =-\gamma_{350} E_{350}^{\mathrm{LH}}, \\
S_{2}^{\mathrm{LH}}+S_{2}^{\mathrm{SH}} & =\gamma_{350} E_{350}^{\mathrm{LH}}-\gamma_{650}\left(E_{650}^{\mathrm{LH}}+\frac{g}{\Delta P} E^{\mathrm{SH}}\right), \\
S_{3}^{\mathrm{LH}}+S_{3}^{\mathrm{SH}} & =\gamma_{650}\left(E_{650}^{\mathrm{LH}}+\frac{g}{\Delta P} E^{\mathrm{SH}}\right) .
\end{aligned}
$$

Here

$$
\gamma_{j}=\frac{1+\tanh [10(\sin \phi-1 / 2)]}{2} \frac{R_{a} \Delta P}{\lambda_{j}^{2} f_{0} c_{p}} P_{j},
$$

where $R_{a}$ is the gas constant for the air, $c_{p}$ the specific heat at constant pressure, $\lambda_{j}$ the deformation radius at 
thermodynamic level $j, f_{0}$ the Coriolis parameter, and $P_{j}=350 \mathrm{hPa}$ or $650 \mathrm{hPa}$ the pressure of the thermodynamic level under consideration. As explained in LLR11, $\gamma_{j}$ should behave as $1 / f_{0}$. To prevent latent heat release in the tropics (and in the Southern Hemisphere), we multiply $\gamma_{j}$ by $\{1+\tanh [10(\sin \phi-1 / 2]\} / 2$ which passes from 0 to 1 around $30^{\circ} \mathrm{N}$.

\section{$b$. The moisture mixing term}

The term $D\left(m_{j}\right)$ in Eq. (6) has the form

$$
\begin{aligned}
& D\left(m_{350}\right)=-\frac{F(\phi)}{\tau_{m}}\left(m_{350}-m_{350}^{s} \frac{m_{650}}{m_{650}^{s}}\right), \\
& D\left(m_{650}\right)=-\frac{F(\phi)}{\tau_{m}}\left(m_{650}-m_{650}^{s} \frac{m_{350}}{m_{350}^{s}}\right) .
\end{aligned}
$$

The ratio $m_{j} / m_{j}^{s}$ is the relative humidity in the layer $j$ and $\tau_{m}$ is a time constant. Equation (A3) parameterizes convective exchange between the layers (i.e., vertical mixing). In our model, the only source of moisture is the evaporation from the ocean, which adds water solely in the lower layer. In other words, the role of the term $D\left(m_{j}\right)$ is to raise water vapor to the upper level. The term $F(\phi)$ mimics the meridional overturning Hadley cell, which is absent in the QG approximation. Its expression is

$F(\phi)=\{1-100[\sin (\phi-\varphi)]\} \exp \{-40[\sin (\phi-\varphi)]\}$,

where $\varphi=5^{\circ} \mathrm{S}$. The condensation scheme is fully described in LLR11.

\section{REFERENCES}

Bordi, I., K. Fraedrich, M. Ghil, and A. Sutera, 2009: Zonal flow regime changes in a GCM and in a simple quasigeostrophic model: The role of stratospheric dynamics. J. Atmos. Sci., 66 , 1366-1383.

Brayshaw, D. J., B. Hoskins, and M. Blackburn, 2008: The stormtrack response to idealized SST perturbations in an aquaplanet GCM. J. Atmos. Sci., 65, 2842-2860.

Businger, J., and W. J. Shaw, 1984: The response of the marine boundary layer to mesoscale variations in sea-surface temperature. Dyn. Atmos. Oceans, 8, 267-281, doi:10.1016/03770265(84)90012-5.

Caballero, R., and P. L. Langen, 2005: The dynamic range of poleward energy transport in an atmospheric general circulation model. Geophys. Res. Lett., 32, L02705, doi:10.1029/ 2004 GL021581.

D'Andrea, F., and R. Vautard, 2001: Extratropical low-frequency variability as a low-dimensional problem. I: A simplified model. Quart. J. Roy. Meteor. Soc., 127, 1357-1374.

Feliks, Y., M. Ghil, and E. Simonnet, 2004: Low-frequency variability in the midlatitude atmosphere induced by an oceanic thermal front. J. Atmos. Sci., 61, 961-981.
,-- , and -2007 : Low-frequency variability in the midlatitude baroclinic atmosphere induced by an oceanic thermal front. J. Atmos. Sci., 64, 97-116.

Ferreira, D., and C. Frankignoul, 2005: The transient atmospheric response to midlatitude SST anomalies. J. Climate, 18, 10491067.

Frankignoul, C., 1985: Sea surface temperature anomalies, planetary waves, and air-sea feedback in the middle latitudes. Rev. Geophys., 23, 357-390, doi:10.1029/RG023i004p00357.

Frierson, D. M. W., I. M. Held, O. Pauluis, and P. Zurita-Gotor, 2006: A gray-radiation aquaplanet moist GCM. Part I: Static stability and eddy scale. J. Atmos. Sci., 63, 2548-2566.

Held, I. M., 2000: The general circulation of the atmosphere. Proc. Prog. Geophys. Fluid Dyn., Woods Hole, MA, WHOI. [Available online at http://hdl.handle.net/1912/15.]

_- M. Ting, and H. Wang, 2002: Northern winter stationary waves: Theory and modeling. J. Climate, 15, 2125-2144.

Holton, J., 1992: An Introduction to Dynamic Meteorology. 3rd ed. Academic Press, 511 pp.

Hoskins, B. J., and P. J. Valdes, 1990: On the existence of stormtracks. J. Atmos. Sci., 47, 1854-1864.

Hotta, D., and H. Nakamura, 2011: On the significance of sensible heat supply from the ocean in the maintenance of mean baroclinicity along storm tracks. J. Climate, 24, 3377-3401.

Inatsu, M., H. Mukougawa, and S.-P. Xie, 2002: Tropical and extratropical SST effects on the midlatitude storm track. J. Meteor. Soc. Japan, 80, 1069-1076.

Kodama, C., and T. Iwasaki, 2009: Influence of the SST rise on baroclinic instability wave activity under an aquaplanet condition. J. Atmos. Sci., 66, 2272-2287.

Kondrashov, D., K. Ide, and M. Ghil, 2004: Weather regimes and preferred transition paths in a three-level quasigeostrophic model. J. Atmos. Sci., 61, 568-587.

Koo, S., and M. Ghil, 2002: Successive bifurcations in a simple model of atmospheric zonal-flow vacillation. Chaos, 12, 300309, doi:10.1063/1.1468249.

—, A. W. Robertson, and M. Ghil, 2002: Multiple regimes and low-frequency oscillations in the Southern Hemisphere's zonal-mean flow. J. Geophys. Res., 107, 4596, doi:10.1029/ 2001JD001353.

Kravtsov, S., A. W. Robertson, and M. Ghil, 2005: Bimodal behavior in the zonal mean flow of a baroclinic $\beta$-channel model. J. Atmos. Sci., 62, 1746-1769.

$\longrightarrow,-$, and,- 2006 : Multiple regimes and low-frequency oscillations in the Northern Hemisphere's zonal-mean flow. J. Atmos. Sci., 63, 840-860.

Kushnir, Y., and N.-C. Lau, 1992: The general circulation model response to a North Pacific SST anomaly: Dependence on time scale and pattern polarity. J. Climate, 5, 271-283.

, W. A. Robinson, I. Bladé, N. M. J. Hall, S. Peng, and R. Sutton, 2002: Atmospheric GCM response to extratropical SST anomalies: Synthesis and evaluation. J. Atmos. Sci., 15, 2233-2256.

Laîné, A., G. Lapeyre, and G. Rivière, 2011: A quasigeostrophic model for moist storm tracks. J. Atmos. Sci., 68, 1306-1322.

Lapeyre, G., and I. M. Held, 2004: The role of moisture in the dynamics and energetics of turbulent baroclinic eddies. J. Atmos. Sci., 61, 1693-1710.

Lu, J., G. Chen, and D. M. W. Frierson, 2010: The position of the midlatitude storm track and eddy-driven westerlies in aquaplanet AGCMs. J. Atmos. Sci., 67, 3984-4000.

Marshall, J., and F. Molteni, 1993: Towards a dynamical understanding of planetary-scale flow regimes. J. Atmos. Sci., 50, 1792-1818. 
Maze, G., F. D'Andrea, and A. Colin de Verdière, 2006: Lowfrequency variability in the Southern Ocean region in a simplified coupled model. J. Geophys. Res., 111, C05010, doi:10.1029/ 2005 JC003181.

Minobe, S., A. Kuwano-Yoshida, N. Komori, S.-P. Xie, and R. J. Small, 2008: Influence of the Gulf Stream on the troposphere. Nature, 452, 206-209, doi:10.1038/nature06690.

Nakamura, H., and A. Shimpo, 2004: Seasonal variations in the Southern Hemisphere storm tracks and jet streams as revealed in a reanalysis dataset. J. Climate, 17, 1828-1844.

T. Sampe, Y. Tanimoto, and A. Shimpo, 2004: Observed associations among storm tracks, jet streams, and midlatitude oceanic fronts. Earth's Climate: The Ocean-Atmosphere Interaction, Geophys. Mongr., Vol. 147, Amer. Geophys. Union, 329-345.

, - A. Goto, W. Ohfuchi, and S.-P. Xie, 2008: On the importance of midlatitude oceanic frontal zones for the mean state and dominant variability in the tropospheric circulation. Geophys. Res. Lett., 35, L15709, doi:10.1029/2008GL034010.

Nonaka, M., H. Nakamura, B. Taguchi, N. Komori, A. KuwanoYoshida, and K. Takaya, 2009: Air-sea heat exchanges characteristic of a prominent midlatitude oceanic front in the south Indian Ocean as simulated in a high-resolution coupled GCM. J. Climate, 22, 6515-6535.

Opsteegh, J. D., R. J. Haarsma, F. M. Selten, and A. Kattenberg, 1998: ECBILT: A dynamic alternative to mixed boundary conditions in ocean models. Tellus, 50A, 348-367, doi:10.1034/ j.1600-0870.1998.t01-1-00007.x.

Palmer, T. N., and Z. Sun, 1985: A modelling and observational study of the relationship between sea surface temperature in the north-west Atlantic and the atmospheric general circulation. Quart. J. Roy. Meteor. Soc., 111, 947-975, doi:10.1002/ qj. 49711147003.

Peixoto, J. P., and A. H. Oort, 1992: Physics of Climate. American Institute of Physics, $520 \mathrm{pp}$.
Rodwell, M. J., D. P. Rowell, and C. K. Folland, 1999: Oceanic forcing of the wintertime North Atlantic oscillation and European climate. Nature, 398, 320-323, doi:10.1038/18648.

Sampe, T., H. Nakamura, A. Goto, and W. Ohfuchi, 2010: Significance of a midlatitude SST frontal zone in the formation of a storm track and an eddy-driven westerly jet. J. Climate, 23, 1793-1814.

Schneider, T., P. A. O'Gorman, and X. Levine, 2010: Water vapor and the dynamics of climate changes. Rev. Geophys., 48, RG3001, doi:10.1029/2009RG000302.

Small, R. J., S. P. DeSzoeke, S. P. Xie, L. O’Neill, H. Seo, Q. Song, and P. Cornillon, 2008: Air-sea interaction over ocean fronts and eddies. Dyn. Atmos. Oceans, 45, 274-319.

Smith, K. S., G. Boccaletti, C. C. Henning, I. Marinov, C. Y. Tam, I. M. Held, and G. K. Vallis, 2002: Turbulent diffusion in the geostrophic inverse cascade. J. Fluid Mech., 469, 13-48, doi:10.1017/ S0022112002001763.

Son, S., and S. Lee, 2005: The response of westerly jets to thermal driving in a primitive equation model. J. Atmos. Sci., 62, 37413757.

Sweet, W., R. Fett, J. Kerling, and P. La Violette, 1981: Air-sea interaction effects in the lower troposphere across the north wall of the Gulf Stream. Mon. Wea. Rev., 109, 1042-1052.

Taguchi, B., H. Nakamura, M. Nonaka, and S. P. Xie, 2009: Influences of the Kuroshio/Oyashio extensions on air-sea heat exchanges and storm-track activity as revealed in regional atmospheric model simulations for the 2003/04 cold season. J. Climate, 22, 6536-6560.

Trenberth, K. E., 1991: Storm tracks in the Southern Hemisphere. J. Atmos. Sci., 48, 2159-2178.

Uppala, S. M., and Coauthors, 2005: The ERA-40 Re-Analysis. Quart. J. Roy. Meteor. Soc., 131, 2961-3012, doi:10.1256/qj.04.176.

Walker, C. C., and T. Schneider, 2006: Eddy influences on Hadley circulations: Simulations with an idealized GCM. J. Atmos. Sci., 63, 3333-3350. 